\title{
內聽道 $\mathrm{X}$ 線撮影法
}

福 渡 六 郎

[日本赤十字社大阪支部病院耳囪咽喉科(主任二本杉祭長)〕

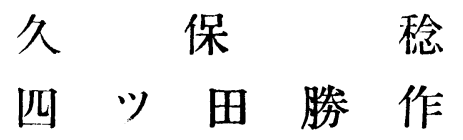

[日本赤十字社大阪支部病院レントゲン科]

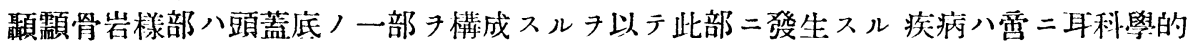

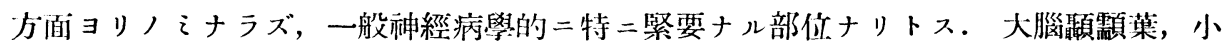

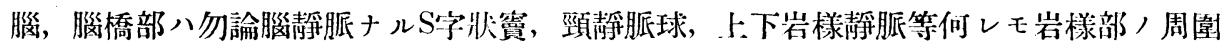

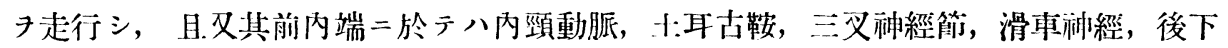
方二於テハ迷走神經, 副神經卜親密ナル局所解剖的關係み有シ, 事實臨床的二此部，

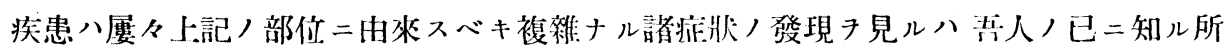

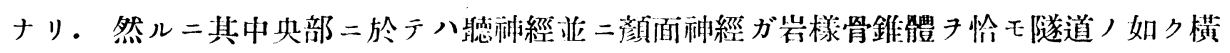
斷シテ走行スル內聽道アリ。從來此內㯖道内二於ケル病變ニツイテハ, 聽湫經亚二顏

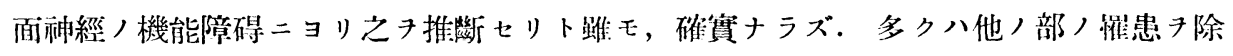

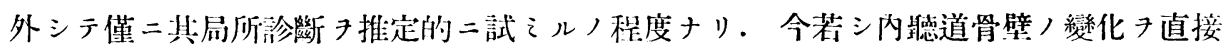
月擊シ得レバ其勃果ハ耳科並二神經學上抄小ニ非ザルナリ。

余八偶々聽神經腫瘍ノ一患者二內㮩道X線撮影法キ試ントシテ, 文献ョリ Stenvers,

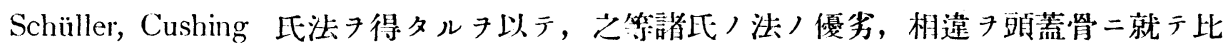
較シ, 最後二余ノ行へル法丹述べン.

\section{Stenvers 氏法}

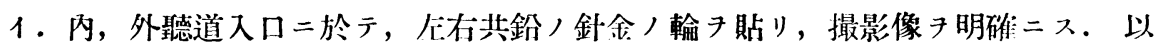
下以レモ同一ノ頭蓋骨キ用ヒタリ。

ロ. 竄真板ハ水本トナシ, 撮影セントスル耳ォ舄眞板ノ中央ニオク,

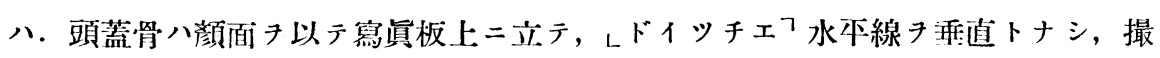

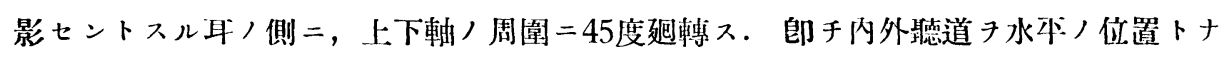
セリ.

ニ.レレントゲンフ線八上下軸二本行ニシテ, 撮影七ントスル外聽道口ト同側，眼

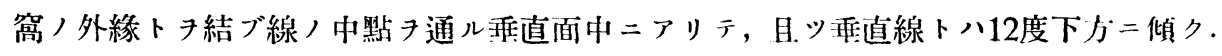




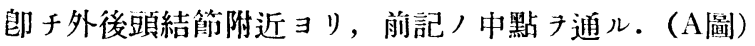

Stenvers ノ法

Fig. A 1 .

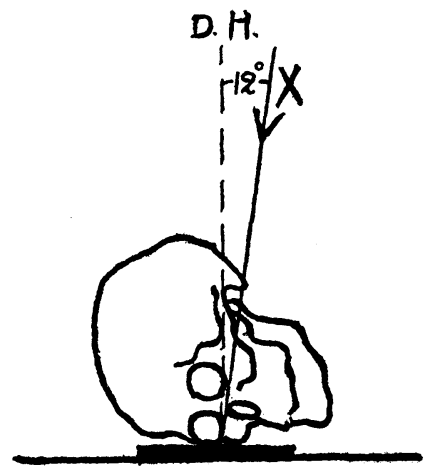

Fig. A 2 .

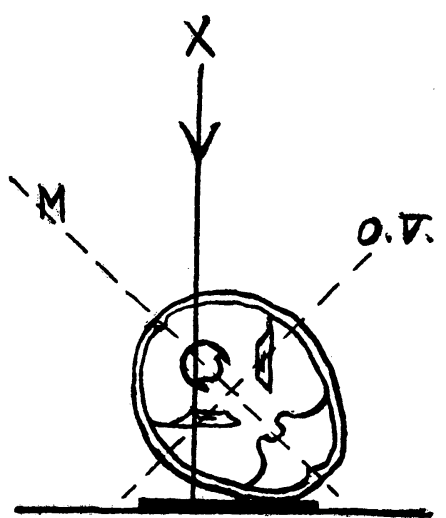

ホ. 管球. レアルゴン?.

へ. 硬度. レベノアーフ 5 度

ト. 遮光板. レチウブスフノ長サハ20粴, 直徑ハ21糎.

チ. 電厴， 135.0 K.V. 䉓流，40. M.A.P.(丸中製アホ、機)以下同機

リ. 焦點距離. 65 粧.

又. 時間. 2 秒.

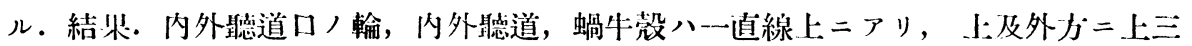
本規管及水本:三牛規管アリ。们レモ甚ダ明䀲ナリ。

\section{Schüller 氏法}

1. 傁貪板八水本ト久.

ロ、頭蓋胃ハ側位キトリ，撮影七ントスル耳キト方二オク。前後軸及上下軸丹水本 トナス.

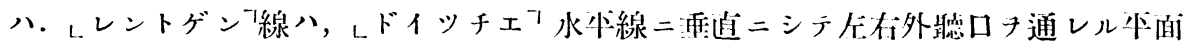
内ニアリ，且ツ再直線トハ上方二30度開キ，撮影七ントスル耳丹通ル。(B皜)

ニ・レレントゲン裝置八前二同ジ.

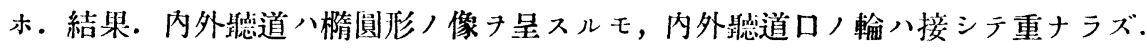

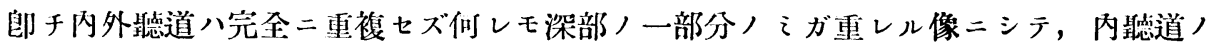
完全ナル像ニ非ズ. 
Fig. B 1.

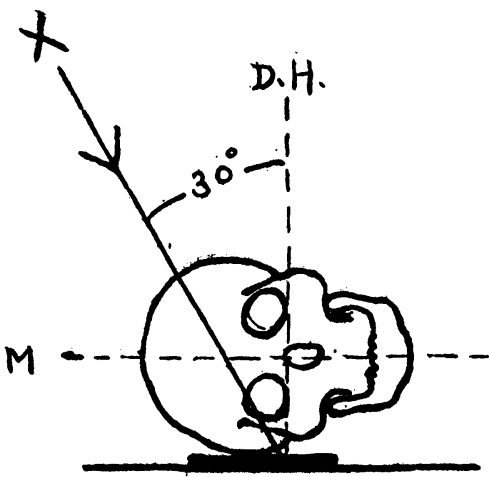

Fig. B 2.

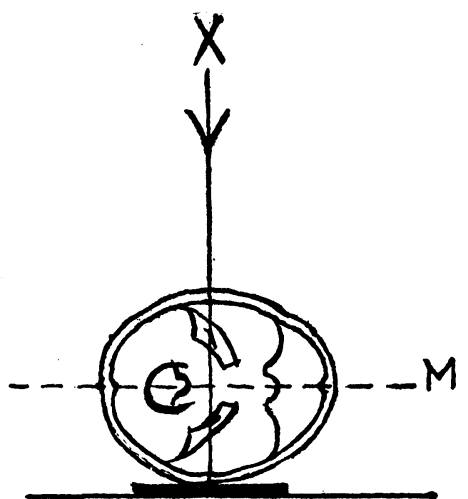

X.........Röntgen 線ノ方向

D.H. ........ Deutsche Horizontallinie

O.V. Ohrvertikal

M. ......... Mittellinic

\section{Cushing 氏法}

イ、舄筫板ハ上力

口. 撮影七ントスル耳キ下二, 側位トナシ, 前後徑ニ於テ後方キ10度高ク, 上下軸 ニオイテ，上方キ15度高ク倾ク。

八.レレントゲンフ線ハ上方ナル外驄道口ノ上後方3糎（生體ナラバ耳翼ノ後上角），

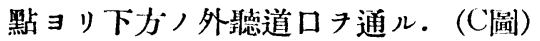

Fig. C 1.

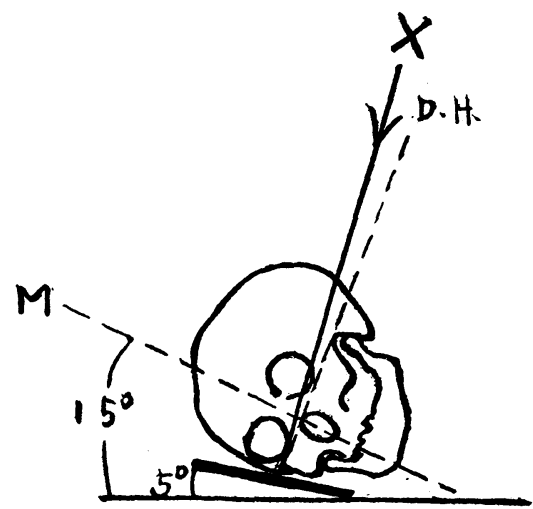

Fig. C 2.

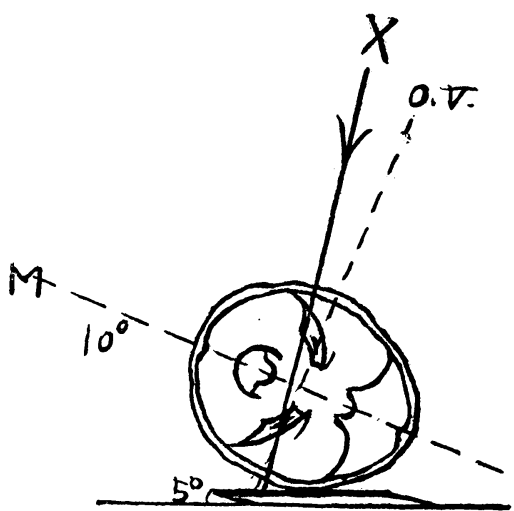

二。管球以下時間マデ前二同ジ.

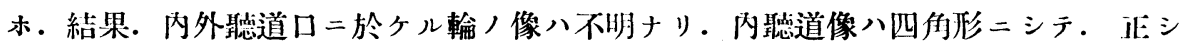


キ像二非ズ。

\section{4. 余ノ行へル撮影法}

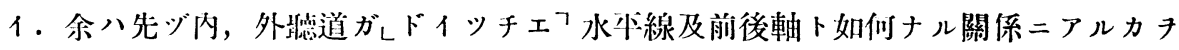
知ラント欲シ，概水斗線及前後軸二鉛ノ針金尹貼リ，顽蓋骨丹正シク水本及卧位トナ

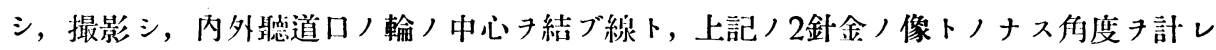

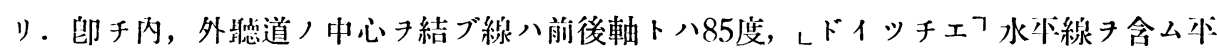

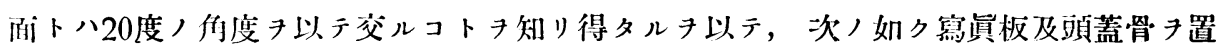
n.

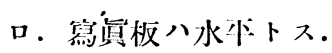

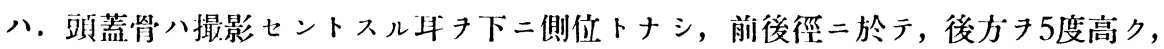
上下軸ニオイテ，上才お

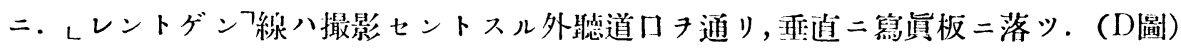
余, 法

Fig. D) 1 .

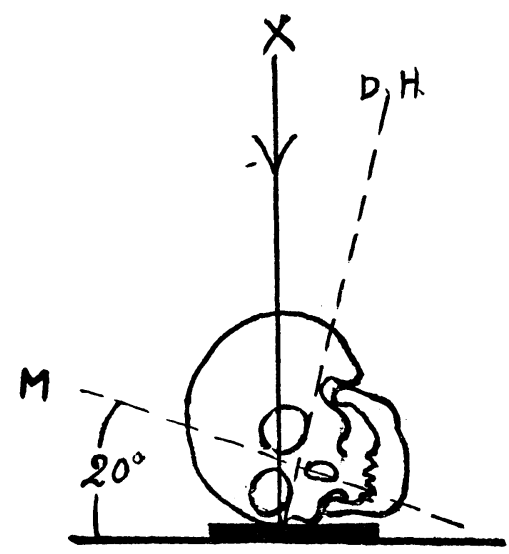

Fig. D 2 .

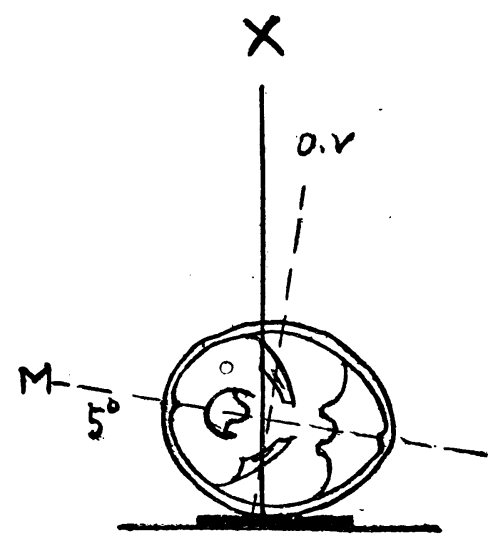

ホ.レレントゲン装蜀八前二同ジ。

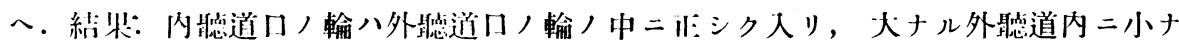
ル內秘道ガ川ジ重ナリ。透明ナル内摘道像八周園，黑キ胃質像ト明カ二區別スルコ 卜子得.

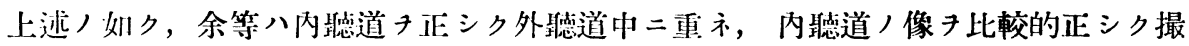

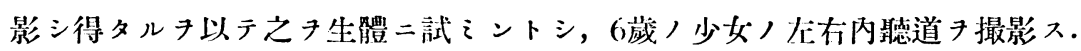

1. 管球. レハンザーフ.

口. 硬度以下焦墨距離マデ前二同ジ。 
八. 時間. 4 秒.

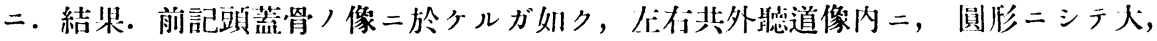
且明㫿ナル內聽道像キ得タリ。

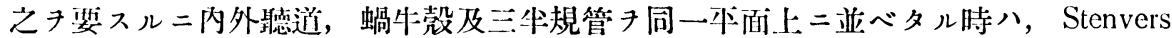

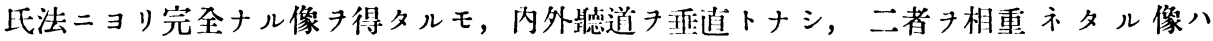
Schüller 及 Cashing 氏法ニョリテハ, 十分ナル像丹得タリト言フベカラズ. 然ル二余

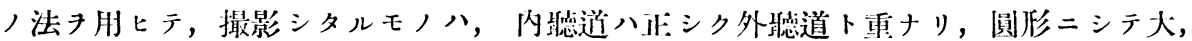

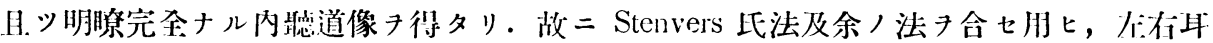

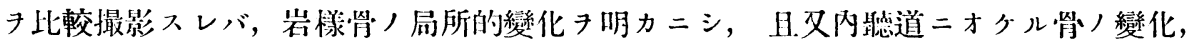

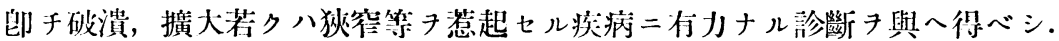

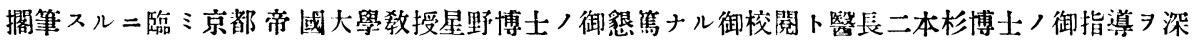
謝 $ᄌ$.

\section{要 主 文 献}

1) V. Sonnenkalb-Chemnitz, Röntgendiagnostik. Denker-Kahler. IJandluch d. II.N.(). IIeilkunde. Bri. VI. S. 1048.

2) Cushing, The Acustic Tumor. 1917.

Mayer, E. G., Ergelonisse der Röntgenologischen Untersuchung des Schläfenbeins bei Erkrankungen des Ohres. Fortsch. a. d. Geb. a. Röntg. Bd. 32.

Otologische Röntgendiagnostik. IIandbuch. d. Röntgenkund Bd. Ir.

4) Mayer, E. G.,

Kurae Inhaltsangalie.

\section{Eine neue Methode zur Röntgenaufnahme des inneren Gehörganges.}

Von

R. Iukuwathit, M. Kubo und K. Yótudi.

Aus den oto-rhino-und laryngologischen Institut des Hospitals des Vereins vom Roten Kreuze zu Osaka. [Direktor: Dr. K. NiHonsuriI und Prof. T. Hoshino an der Kaiserlichen Uniuversität zu Kyoto.]

Verfasser nehmen das Röntgenogramm des inneren Gehürgangs mit einer neuen Methode auf.

1) Die Kinn-Nasenlinie bldet einen scheitelwärts offenen Winkel von $20^{\circ}$ und die Sagittalacshe einen hinterwärts offenen Winkel vom $5^{\circ} \mathrm{mit}$ der horizontalen Kassette. 

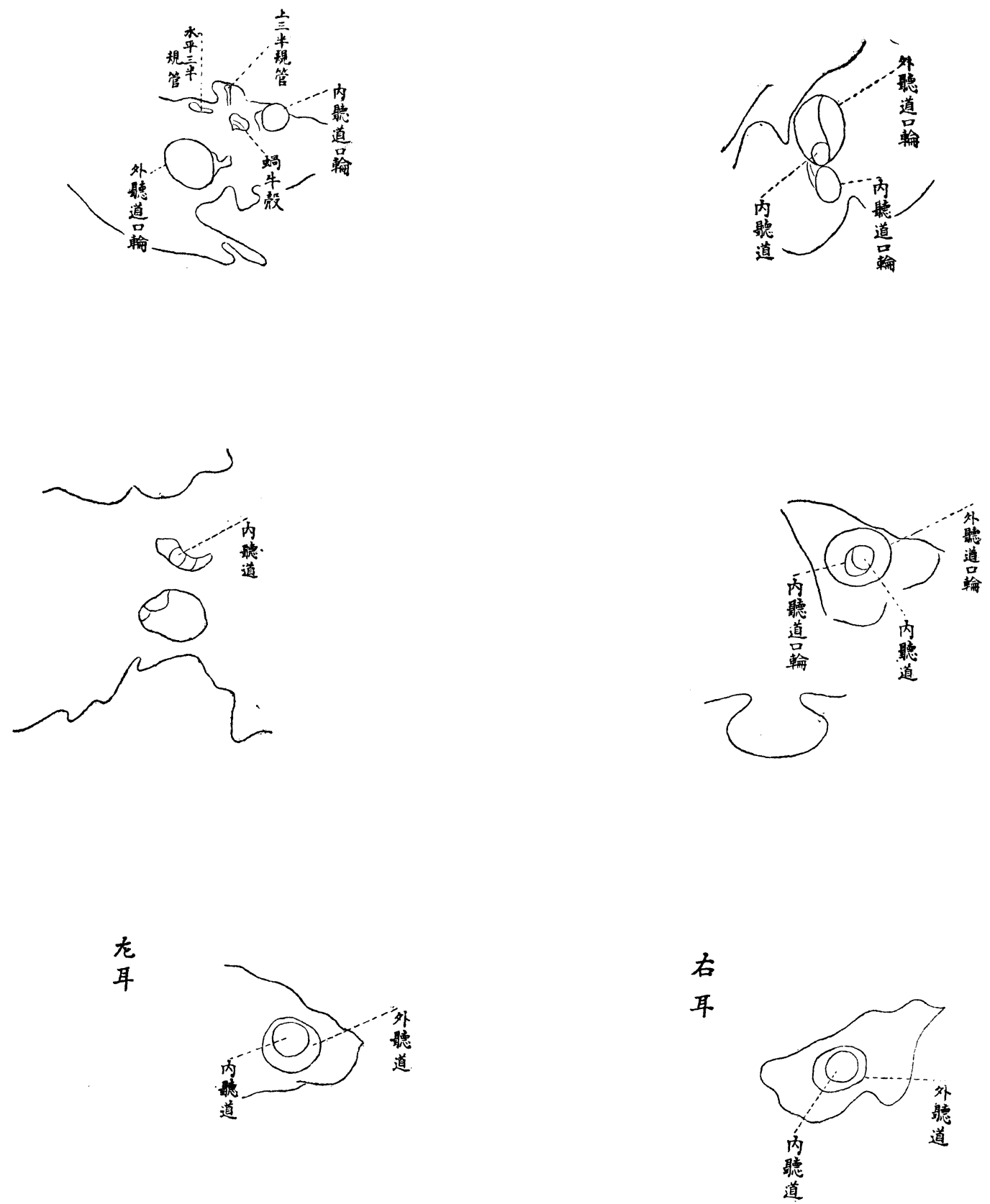
福渡, 久保, 四ツ田論文附圖

Stenvers 氏法 A

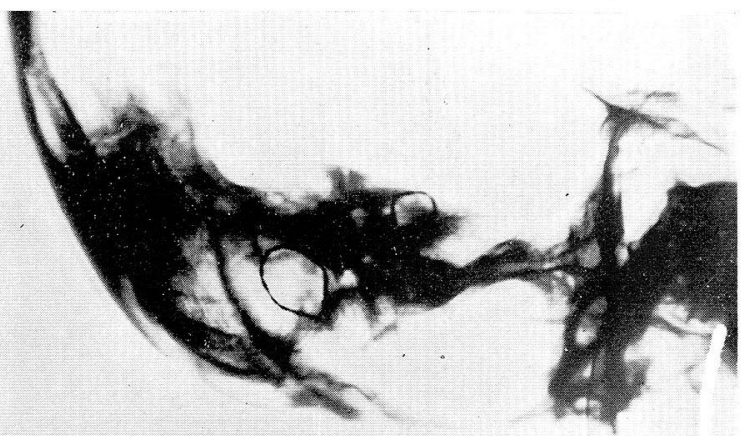

Cushing 氏法 C

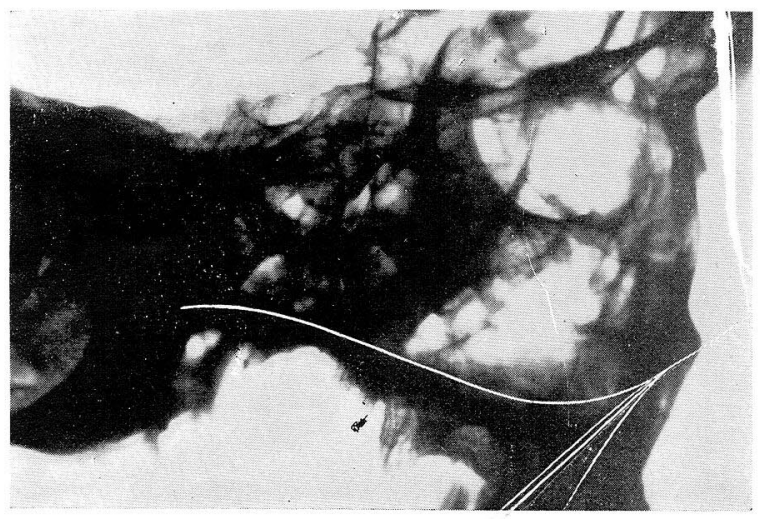

E

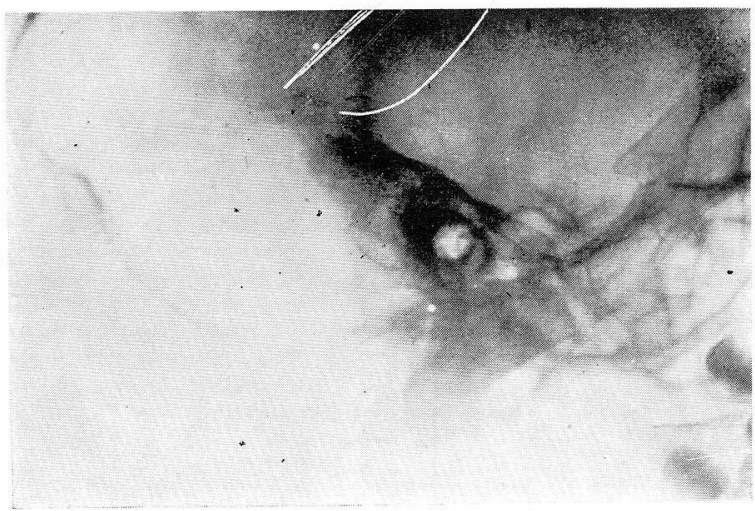

Schüller 氏法 1!

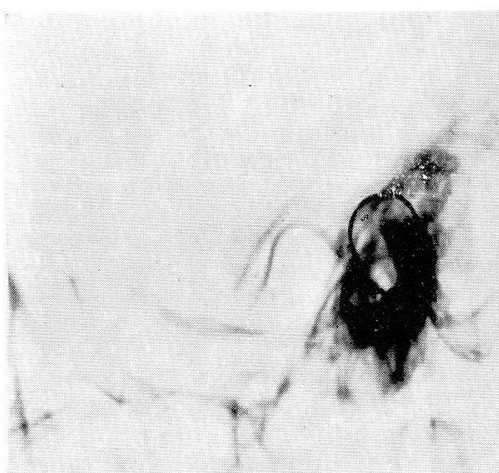

福渡, 法 D

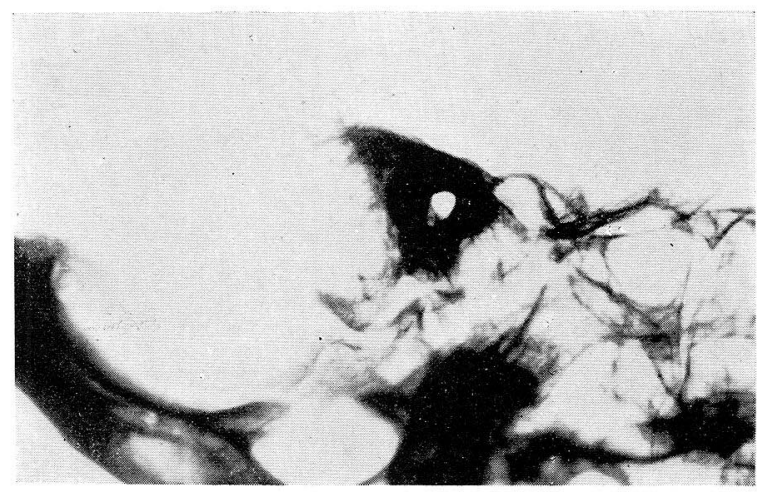

F

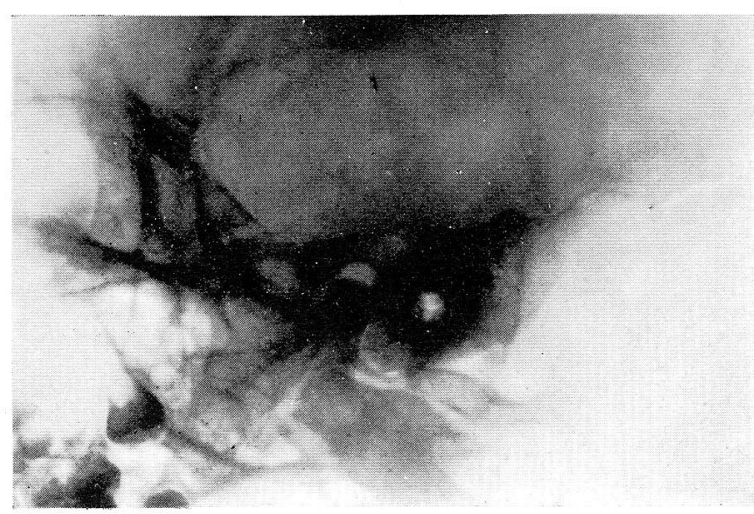


2) Die Röntgenstrahlen werden senkrecht auf dis unteren aufzunehs enden Ohr eingestellt.

Auf diese Weise kömen Verfisser den rundlichen Schatt n des inneren Gehörganges in der Mitte des grossen Schattens des aiisseren Gehörgangs darstellen. 